\title{
DEVELOPING A HYBRID MULTI-CRITERIA MODEL FOR SELECTION OF OUTSURCING PROVIDERS
}

\author{
James J.H. Liou* \\ Department of Air Transportation, Kainan University \\ No. 1, Kainan Road, Luchu, Taoyuan 338, Taiwan \\ E-mail: jhliou@mail.knu.edu.tw \\ Wen-Chien Yeh \\ Department of Air Transportation, Kainan University \\ No. 1, Kainan Road, Luchu, Taoyuan 338, Taiwan \\ E-mail: wcyeh@mail.knu.edu.tw \\ Yu-Che Lo \\ Department of Air Transportation, Kainan University \\ No. 1, Kainan Road, Luchu, Taoyuan 338, Taiwan \\ E-mail: $\underline{\text { m09709004@ms.knu.edu.tw }}$ \\ Chia-Li Lin \\ Department of Air Transportation, Kainan University \\ No. 1, Kainan Road, Luchu, Taoyuan 338, Taiwan \\ E-mail: $\underline{\text { m09709005@ms.knu.edu.tw }}$
}

\begin{abstract}
Outsourcing is a good strategy for firms that need to reduce operating costs and improve competitiveness, but it remains important for firms to scientifically select the appropriate outsourcing providers. Some efforts have been made regarding outsourcing problems, but these efforts incorrectly assumed that the criteria in the decision process are independent, which is not true in the real world. In this paper, we propose a new hybrid multiple criteria decision-making (MCDM) model, which addresses the dependent relationships among criteria with the aid of the Decision-Making Trial and Evaluation Laboratory (DEMATEL) method to build a relations-structure among criteria. The Analytical Network Process (ANP) is used to determine the relative weights of each criterion with dependence and feedback. The VIKOR method (VlseKriterijumska Optimizacija I Kompromisno Resenje in Serbian, meaning Multi-criteria Optimization and Compromise Solution) is then used to prioritize the alternatives. The proposed model can help practitioners improve their decision process, especially when criteria are numerous and inter-related. Throughout our study, we use data from a Taiwanese airline to demonstrate this method.
\end{abstract}

Keywords: Outsourcing; VIKOR; ANP; Decision-Making Trial and Evaluation Laboratory (DEMATEL); MCDM

\footnotetext{
${ }^{*}$ Corresponding author. Tel.: +886 33412500 ext. 6064; fax: +888 33016912.
} 


\section{Introduction}

Outsourcing can be simply defined as devising a contract with an external organization to take primary responsibility of providing business processes (Yang, Kim, Nam, \& Min, 2007). Business outsourcing has become an ever-increasing trend in today's highly competitive markets. Firms can either embark on internal off-shoring (by setting up their own centers or subsidiaries in foreign countries while maintaining full ownership and control) or external off-shoring (by handing over business functions to independent foreign providers). Interest is growing among strategy and international business scholars to better understand how outsourcing can be used as a strategic device, or sometimes as a strategy itself, in order to create value (Kedia \& Mukherjee, 2008). But the concept of outsourcing is not new. External service providers in areas such as facilities operations, finance, accounting, logistics, legal services, marketing, and customer care have existed for a long time. However, elements such as new technologies, delivery models, globalization, and a more demanding end-user continue to provide impetus for outsourcing activities (Yang, Kim, Nam, \& Min, 2007). The result - firms' increased efficiencies and abilities to focus on core competencies - has produced real profits and increased customer satisfaction. Nevertheless, ineffective outsourcing activities, derived from improper strategies or methods, will lead to a loss of core competencies and capabilities, exposure to unexpected risk, and business failures (Wang \& Yang, 2007). Therefore, a scientific decision process for choosing outsourcing providers is very important to increasing the success rate of outsourcing.

Early researchers most commonly illustrated outsourcing decisions by using transaction cost theory. However, in recent years, strategy aspects such as core competency, risk analysis, and organizational flexibility have been growing in importance. As a result, this trend has led researchers and industries to become more interested in the multi-criteria decision model for outsourcing. The goal of the multiple criteria decision-making (MCDM) method is to aid decision-makers in integrating objective measurements with value judgments which are not based on individual opinions, but rather on collective group ideas (Belton, 2002). Some researchers (Yang, Kim, Nam, \& Min, 2007; Wang \& Yang, 2007) have applied the MCDM method to different outsourcing issues. But their work assumed the criteria were independent, and used AHP (analytic hierarchical process) to construct a model of the outsourcing problems. In the real world, criteria are seldom independent and always have a degree of interactive relationships, sometimes with dependence and feedback effects (Tzeng, Chiang, \& Li, 2007; Tsai \& Chou, 2009).

In this paper, we shall use the DEMATEL method to construct the interrelationship between criteria, and will also use the ANP method (which releases the restriction of the hierarchical structure) to determine the weights of criteria. We will then use the VIKOR method to prioritize the alternatives. Therefore, the objective of this paper is to offer a quantitative decision model that can help practitioners set priorities and reap the most benefits from outsourcing. We use data from a Taiwanese airline to demonstrate this model. This genetic model can be easily extended to other industries, helping other types of firms to maximize their outsourcing benefits.

The rest of this paper is structured as follows. Section 2 summarizes some important previous research regarding outsourcing and describes problem characteristics. Section 3 reviews the basic concepts of the DEMATEL, ANP, and VIKOR. Section 4 illustrates an empirical example used to validate our model. The results and discussions of this empirical study are presented in Section 5 . Section 6 contains the conclusions and final remarks.

\section{A brief review in outsourcing}

Outsourcing occurs when one company hands over a part of their existing internal activity to another company via contract (McCarthy \& Anagroustou, 2004). The purpose of outsourcing is to create value from outside, rather than within, the company. Outsourcing has become an important business approach, and competitive advantages are often gained as products or services are produced more efficiently by outside suppliers (Yang, Kim, Nam, \& Min, 2007). Outsourcing could be used by and for a company to strengthen its position in today's competitive markets.

The main reasons for outsourcing usually include cost savings, a focus on core competency, and flexibility in management. Although cost savings are still a very important consideration, Hamel and Prahalad (1994) argue that companies which measure competitiveness solely in terms of price 
are actually contributing to the erosion of their core competence. Their main idea is that only products and services, which are regarded as core competencies, should be produced internally. Outsourcing non-core activities also increases flexibility through better use of international resources; it enables quick responsiveness to customer needs and decreases financial risk by reducing capital investments (Ellram, Tate, \& Billington, 2008). However, management needs to carefully consider the related shortcomings of outsourcing along with its benefits. The generally recognized disadvantages include: information security, loss of management control, morale problems, and labor union issues. Furthermore, many companies have found that outsourcing activities have introduced unexpected complexities, added costs and friction to the value chain, and required more senior management attention and deeper management skills than initially anticipated (Howells, 1999).

The majority (around 70\%) of the U.S. industry appears to have had negative experiences with outsourcing (Verma, 2005). This is a result of a lack of comprehensive evaluations, which can be used to come up with the best candidates for outsourcing. With this acknowledgement, there have been a number of studies determining the most effective manner of selecting outsourcing providers. Hsu and Hsu (2008) presented an entropy-combined technique for order preference by similarity to ideal solution (TOPSIS) based decision-making method for medical information system outsourcing. Sarder et al. (2006) conducted outsourcing SWOT analyses for some U.S. industries. They concluded that there was no correct answer to choosing the best outsourcing strategies and that many criteria/factors should be considered in the process. Lee and Kim (2005) analyzed the structural relationship among the determinants of an outsourcing partnership and identified the relationship between partnership-related variables and outsourcing success. They identified six key factors of a successful partnership in areas of outsourcing, working partnerships in marketing, and strategic alliances in management. Their proposed six inter-relative key factors are: shared knowledge, organizational linkage, mutual dependency, benefits, commitment, and predisposition. Some other researchers (Yang, Kim, Nam, \& Min, 2007; Wang \& Yang, 2007) have used different MCDM models to investigate information systems outsourcing. However, these studies did not consider the inter-relationship between criteria. Jharkharia and Shankar (2007) applied the ANP method to help firms select logistics service providers but did not clarify how to generate the relationship between criteria. Our new approach, a hybrid model combining the DEMATEL, ANP, and VIKOR methods, accounts for the more complex relationships among relative criteria/factors and feedback effects, and can be utilized as an outsourcing decision model for the airline industry (and may also be easily extended to other industries in the real world).

\section{Proposed model: a novel hybrid model of DEMATEL, ANP, and VIKOR}

In this section, we introduce the concepts of the DEMATEL (to establish the relations- structure model in evaluation problem), ANP (to determine criteria weights with dependence and feedback) and VIKOR (to prioritize alternatives) models.

\subsection{Clarifying the interrelation between criteria}

In a complex system, all system criteria are either directly or indirectly mutually related. Therefore, in such intricate systems, it is very difficult for a decision-maker to obtain a specific objective/aspect if he/she wants to avoid interference from the rest of the system. While the vision of a totally interdependent system leads to passive positions, the vision of a clearer hierarchical structure leads to linear activism, which neglects dependence and feedback and may also engineer many new problems in the process of solving others (Tzeng, Chiang, \& Li, 2007).

The DEMATEL approach, used for researching and solving complicated and intertwined problems, was successfully applied in many areas, such as marketing strategies, e-learning evaluations, control systems, safety problems, and cause analyses (Chiu, Chen, \& Tzeng, 2006; Tzeng, Chiang, \& Li, 2007; Tamura et al., 2002; Tseng, 2009). DEMATEL was developed with the belief that the pioneering and appropriate use of scientific research methods could improve understandings of the specific problematique (the cluster of intertwined problems) and help identify workable solutions through a network structure. This methodology, according to the concrete characteristics of 
objective affairs, can confirm the interdependence among the variables/criteria and restrict the relations that reflect characteristics with essential system and development trends. The end product of the DEMATEL process is a visual representation that a respondent can use to organize his or her own actions in the world (Liou, Tzeng, \& Chang, 2007).

The DEMATEL method can be summarized in the following steps:

Step 1: Calculate the initial average matrix by scores. Respondents were asked to indicate the direct effect that they believe each element $i$ exerts on each element $j$ of others, as indicated by $a_{i j}$, according to an integer scale (scores) ranging from 0 to 4, representing: "No influence (0);" "Low influence (1);" "Medium influence (2);" "High influence (3);" and "Very high influence (4)." From any group of direct respondent matrices, we derive an average matrix $\boldsymbol{A}$. In this case, each element of this average matrix will be the mean of the same elements in the different direct matrices of the respondents.

Step 2: Calculate the initial influence matrix. The initial influence matrix $\boldsymbol{D}\left(\boldsymbol{D}=\left[d_{i j}\right]_{n \times n}\right)$ can be obtained by normalizing the average matrix $\boldsymbol{A}$ as shown by degree (i.e., shown by membership and $0 \leq d_{i j}<1$; also called a "fuzzy cognitive matrix"), in which all principal diagonal elements are equal to zero. Based on matrix $\boldsymbol{D}$, the initial effect that an element exerts and receives from another is shown. The map portrays a contextual relation among the elements of a system, in which a numeral represents the strength of influence (affected degree). For example, as shown in Fig. 1, an arrow from $c$ to $d$ represents the fact that $c$ affects $d$, with an influence score of 4. The DEMATEL method can convert the relationship between the causes and effects of criteria into an intelligible structural model of the system by influence-degree.

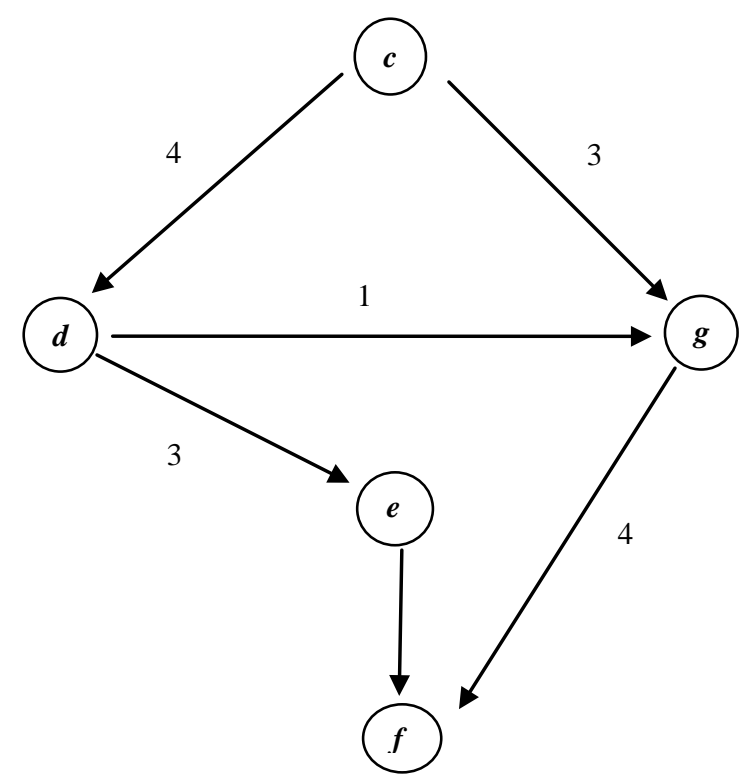

Fig. 1. Illustration of influential map

Step 3: Derive the full direct/indirect influence matrix. A continuous decrease of the indirect effects of problems along the powers of the matrix $D$, e.g. $D^{2}, D^{3}, \ldots, D^{\infty}$, guarantees convergent solutions to the matrix inversion. As shown in Fig. 1, the effect of $c$ on $g$ is greater than the effect of $c$ on $f$, thus illustrating the infinite series of direct and indirect effects. With the $(i, j)$ element of matrix $\boldsymbol{A}$ denoted by $a_{i j}$, the matrix can be gained following four equations:

$$
\boldsymbol{D}=s \cdot \boldsymbol{A}, \quad s>0
$$

or

$$
\left[d_{i j}\right]_{n \times n}=s\left[a_{i j}\right]_{n \times n}, s>0, i, j \in\{1,2, \ldots, n\}
$$


where $s=\operatorname{Min}\left[\frac{1}{\max _{1 \leq i \leq n} \sum_{j=1}^{n}\left|a_{i j}\right|}, \frac{1}{\max _{1 \leq i \leq n} \sum_{i=1}^{n}\left|a_{i j}\right|}\right]$

(3)

and

$$
\lim _{m \rightarrow \infty} \boldsymbol{D}^{m}=[0]_{n \times n}, \quad \text { where } \boldsymbol{D}=\left[d_{i j}\right]_{n \times n}, 0 \leq d_{i j}<1
$$

(4)

The total-influence matrix $\boldsymbol{T}$ can be obtained by using the following equation (5) where $\boldsymbol{I}$ is denoted as the identity matrix.

$$
\boldsymbol{T}=\boldsymbol{D}+\boldsymbol{D}^{2}+\ldots+\boldsymbol{D}^{\boldsymbol{m}}=\boldsymbol{D}(\boldsymbol{I}-\boldsymbol{D})^{-1} \text {, when } m \rightarrow \infty
$$

If we define the sums of rows and columns separately, denoted as vectors $\boldsymbol{r}$ and $\boldsymbol{c}$ within the total-influence matrix $\boldsymbol{T}$ through equations (6), (7), and (8), then:

$$
\begin{aligned}
& \boldsymbol{T}=\left[t_{i j}\right], \quad i, j=1,2, \ldots, n \\
& \boldsymbol{r}=\left[r_{i}\right]_{n \times 1}=\left(\sum_{j=1}^{n} t_{i j}\right)_{n \times 1} \\
& \boldsymbol{c}=\left[c_{j}\right]_{1 \times n}^{\prime}=\left(\sum_{i=1}^{n} t_{i j}\right)_{1 \times n}^{\prime}
\end{aligned}
$$

where superscript ' denotes transpose.

If $r_{i}$ denotes the row sum of the $i$-th row matrix $\boldsymbol{T}$, then $r_{i}$ shows the sum of direct and indirect effects of factor $i$ on the other factors/criteria. If $c_{j}$ denotes the column sum of the $j$-th column of matrix $\boldsymbol{T}$, then $c_{j}$ shows the sum of direct and indirect effects that factor $j$ has received from the other factors. When $j=i$, this means that the sum of row and column sums $\left(r_{i}+c_{i}\right)$ shows an index representing the strength of influence both given and received; that is, $\left(r_{i}+c_{i}\right)$ shows the degree (total sum of influence given and received) of the central role that factor $i$ plays in the problem. Therefore, if $\left(r_{i}-c_{i}\right)$ is positive, then factor $i$ is affecting other factors; and if $\left(r_{i}-c_{i}\right)$ is negative, then factor $i$ is being influenced by other factors.

Step 4: Set threshold value and obtain the impact relation map. Setting a threshold value, $p$, to filter the obvious effects denoted by the elements of matrix $\boldsymbol{T}$, is necessary to explain the relationship structure between the elements. Based on the matrix $\boldsymbol{T}$, each element $t_{i j}$ of matrix $\boldsymbol{T}$ provides information about how element $i$ affects element $j$. To reduce the complexity of the impact relations map (IRM), the decision-maker must set a threshold value for the influence level. Only some elements, whose influence level in matrix $\boldsymbol{T}$ is higher than the threshold value, can be chosen and converted into the IRM (Liou, Tzeng, \& Chang, 2007)

\subsection{The analytic network process (ANP)}

The ANP, a new theory extending from the AHP, is proposed by Saaty (1996) to overcome the problem of interdependence and feedback between criteria or alternatives. Although both the AHP and ANP derive ratio scale priorities by making paired comparisons of elements on a criterion, there are some differences between the theories. The first difference is that the AHP is a special case of the ANP, because the ANP handles dependence within a cluster (inner dependence) and among different clusters (outer dependence). Second, the ANP is a nonlinear structure, whereas the AHP is 
hierarchical and linear, containing a goal at the top level and alternatives at the bottom level (Saaty, 1999). The first step of the ANP is to compare the criteria in whole systems to form the supermatrix. This is done through pairwise comparisons by asking, "How much importance does a criterion have compared to another criterion with respect to our interests or preferences?” The relative importance value can be determined using a scale of 1 to 9, representing equal importance (1) to extreme importance (9) (Saaty, 1996; Huang, Tzeng, \& Ong, 2005). The general form of the supermatrix can be described as follows:

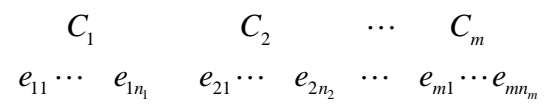

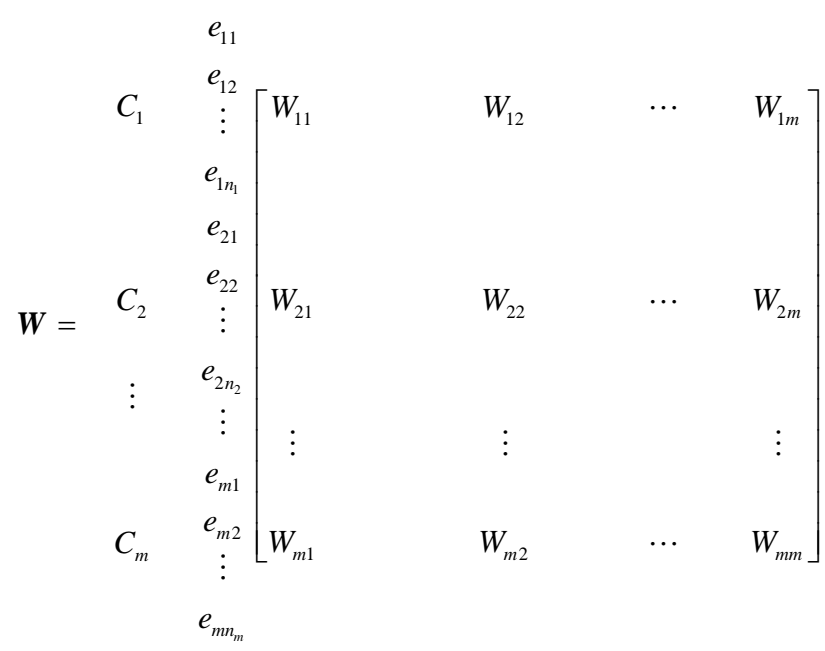

where $C_{m}$ denotes the $m$ th cluster, $e_{m n}$ denotes the $n$th element in $m$ th cluster, and matrix $\boldsymbol{W}_{i j}$ is the principal eigenvector of the influence of the elements compared in the $j$ th cluster to the $i$ th cluster. The form of the supermatrix depends on the variety of the structure. For example, if the structure of the system is shown as Fig. 2, the unweighted supermatrix $\boldsymbol{W}$, which contains local priorities derived from the pairwise comparisons throughout the network, is illustrated as follows:

$$
\begin{aligned}
& \begin{array}{llll}
C_{1} & C_{2} & C_{3}
\end{array} \\
& \boldsymbol{W}=C_{2}\left[\begin{array}{ccc}
C_{1} \\
C_{3}
\end{array}\left[\begin{array}{ccc}
0 & 0 & W_{13} \\
W_{21} & 0 & 0 \\
0 & W_{32} & W_{33}
\end{array}\right]\right.
\end{aligned}
$$

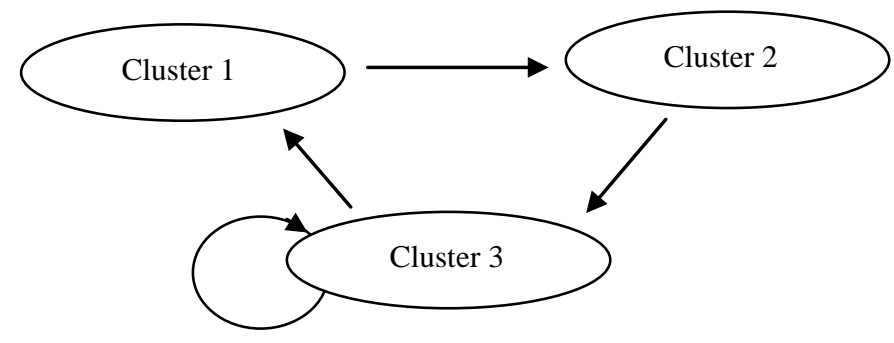

Fig. 2. Illustration of the structure of the system

$\boldsymbol{W}_{21}$ is a matrix that represents the weights of cluster 2 with respect to cluster 1 , matrix $\boldsymbol{W}_{32}$ represents the weights of cluster 3 with respect to cluster 2 , and matrix $\boldsymbol{W}_{13}$ represents the weights of cluster 1 with respect to cluster 3 . In addition, matrix $\boldsymbol{W}_{33}$ is denoted as the inner dependence and feedback within cluster 3 . After forming the supermatrix, the weighted supermatrix is derived by transforming all column sums exactly to unity. This step is very similar to the concept of the Markov chain, used to ensure that the sum of the probabilities of all states equals 1 (Huang, Tzeng, 
\& Ong, 2005). Then, the weighted supermatrix can be raised to limiting powers, as in equation (11), to calculate the overall priorities.

$$
\lim _{k \rightarrow \infty} W^{k}
$$

\subsection{The VIKOR method}

Opricovic (1998) and Opricovic and Tzeng (2004) developed VIKOR method. The basic concept of VIKOR lies in first defining the positive and negative ideal solutions. The positive ideal solution indicates the alternative with the highest value, while the negative ideal solution indicates the alternative with lowest value. The steps for a VIKOR analysis are summarized as follows (Opricovic \& Tzeng, 2007):

Step 1: Calculate the normalized value. To calculate normalized value, when $x_{i j}$ is the original value of the $i$ th option and the $j$ th criterion, the formula is as follows:

$$
f_{i j}=\frac{x_{i j}}{\sqrt{i=\sum_{i=1}^{m} x_{i j}^{2}}}, i=1,2, \ldots, m ; j=1,2, \ldots, n \text {. }
$$

Step 2: Determine the best and worst values. For all criteria functions, the best value is $f_{j}^{*}$ and the worst value is $f_{j}^{-}$; that is, for criterion $j=1, \ldots, n$, we have formulas (13) and (14), illustrated below:

$$
\begin{aligned}
& f_{j}^{*}=\operatorname{Max}_{i} f_{i j}, \quad i=1,2, \ldots, m,(13) \\
& f_{j}^{-}=\operatorname{Min}_{i} f_{i j}, \quad i=1,2, \ldots, m,
\end{aligned}
$$

Where $f_{j}^{*}$ is the positive ideal solution for the $j$ th criterion, and $f_{j}^{-}$is the negative ideal solution for the $j$ th criterion.

Step 3: Compute the distance. This step calculates the distance from each alternative to the positive ideal solution.

$$
\begin{aligned}
& S_{i}=\sum_{j=1}^{n} w_{j}\left(f_{j}^{*}-f_{i j}\right) /\left(f_{j}^{*}-f_{j}^{-}\right) \\
& Q_{i}=\operatorname{Max}_{j}\left[\left(f_{j}^{*}-f_{i j}\right) /\left(f_{j}^{*}-f_{j}^{-}\right)\right]
\end{aligned}
$$

Where $w_{j}$ represents weights of criteria, $S_{i}$ represents the distance of the $i$ th alternative achievement to the positive ideal solution, and $Q_{i}$ implies maximal regret of each alternative.

Step 4: Compute the index value $R_{i}$. These index values are defined as:

$$
R_{i}=v\left[\frac{S_{i}-S^{*}}{S^{-}-S^{*}}\right]+(1-v)\left[\frac{Q_{i}-Q^{*}}{R^{-}-R^{*}}\right]
$$

Where $S^{*}=\operatorname{Min} S_{i}, S^{-}=\operatorname{Max} S_{i}, R^{*}=\operatorname{Min} R_{i}, R^{-}=\operatorname{Max} R_{i}$, and $v$ is the weight of decision-making strategy, representing "the majority of criteria." In equation (17), when $v=1$, it represents a decision-making process that could use the strategy of maximum group utility. On the other hand, when $v=0$, it represents a decision-making process that could use the strategy of minimum 
individual regret. In sum, we not only use the above steps to obtain the best alternative (or projects/objectives) based on the values $\left\{R_{i} \mid i=1,2, \ldots, m\right\}$, which have a minimum value of $\left\{R_{i} \mid i=1,2, \ldots, m\right\}$, but we also use the steps to prioritize the alternatives (or projects/objectives) with respect to the gaps, based on $\left\{R_{i} \mid i=1,2, \ldots, m\right\}$, for improvements. To illustrate the hybrid model, the following numerical examples are proposed.

\section{Empirical example}

In this section, an empirical study for the selection of outsourcing providers in the airline industry is used to illustrate the feasibility of the proposed method.

\subsection{Problem descriptions}

Globalization has resulted in a closely integrated labor and capital market, where firms have greater access to human capital scattered around the world. Without exception, the airline industry is a highly complex business encompassing a variety of professional skills. In order to provide total and effective services, airline operators must overcome the challenges of rapid change, rising competition, rising complexity, and radically-changing environments. As a result, many major airlines are going through de-integration processes as they contract out large parts of their business to networks of suppliers in search of greater efficiency and competitiveness. Nevertheless, the advantages of outsourcing are not always clear; improper outsourcing activities can sometimes lead to a loss of core competencies and capabilities, exposure to unexpected risks, difficulties in implementation and management, and sometimes even business failure. Therefore, we have proposed a hybrid processing model for airlines that can efficiently select strategic partners for outsourcing activities.

The model is developed and then validated using data from Eva Air, a Taiwanese airline that services more than 50 international destinations. In order to reduce manpower costs and provide more efficient services, the company has sought to contract out its ground services in foreign destinations. Los Angeles, California was selected as the case study since it is one of the most important cities in Eva Air's flight networks. The decision is strategic because the development's success will have great bearing on the company's competitive abilities.

\subsection{Partner selection criteria}

In any outsourcing activity, there are risks, such as potential structural and cultural incompatibilities. To ensure success, it is crucial that both users and providers (partners) have a clear understanding of their similarities and differences, recognizing opportunities for mutual benefits under cooperative arrangements. Since partner selection is crucial, it is imperative for decision-makers to devise, identify, and recognize effective partner selection criteria, as well as evaluate questions of compatibility and feasibility prior to outsourcing activities. Several issues are important to determining the optimal collaborator in this partner selection process, including: whether there has been favorable past association between the partners; whether the national and corporate cultures of the partners are compatible; and whether trust exists between the partners' management teams. In this study, the partner selection criteria have been developed on the basis of literature review and a series of discussions with Eva Air's managers. This discussion with the industry helped us to classify the various criteria of decision-making into four dimensions: compatibility, risk, quality, and cost. These dimensions were then divided into various criteria, as indicated in Table 1. By examining these dimensions, we can avoid the pitfalls of classic outsourcing decisions where cost alone is used as the deciding factor.

Table 1. Dimensions and criteria of the evaluating systems

\begin{tabular}{lll}
\hline Dimensions & Criteria & Explanations \\
\hline Compatibility & Relationship $\left(\mathrm{C}_{1}\right)$ & $\begin{array}{l}\text { Includes shared risks and rewards, ensuring cooperation } \\
\text { between the airline and ground service provider. }\end{array}$ \\
& Flexibility $\left(\mathrm{C}_{2}\right)$ & $\begin{array}{l}\text { Flexibility when dealing with abnormal situations, such as } \\
\text { flight delays, overbooking, incidents, etc. }\end{array}$ \\
\hline
\end{tabular}




\begin{tabular}{|c|c|c|}
\hline & $\begin{array}{l}\text { Information } \\
\text { sharing } \\
\left(\mathrm{C}_{3}\right)\end{array}$ & $\begin{array}{l}\text { The compatibility of computer systems and } \\
\text { information-sharing, such as new information/regulations at a } \\
\text { destination airport. }\end{array}$ \\
\hline \multirow[t]{3}{*}{ Quality } & $\begin{array}{l}\text { Knowledge skills } \\
\left(\mathrm{C}_{4}\right)\end{array}$ & $\begin{array}{l}\text { Facilities of the service provider for airplane maintenance } \\
\text { and their knowledge of manpower are essential. }\end{array}$ \\
\hline & $\begin{array}{l}\text { Customers' } \\
\text { satisfactions }\left(\mathrm{C}_{5}\right)\end{array}$ & $\begin{array}{l}\text { The average customer's satisfaction level regarding ground } \\
\text { services such as check-in and luggage handling. }\end{array}$ \\
\hline & On time rate $\left(\mathrm{C}_{6}\right)$ & Ratio that the airplanes are delivered on time. \\
\hline \multirow[t]{2}{*}{ Cost } & Cost saving $\left(\mathrm{C}_{7}\right)$ & The total cost of the outsourcing activities. \\
\hline & $\begin{array}{l}\text { Flexibility in } \\
\text { billing } \\
\left(\mathrm{C}_{8}\right)\end{array}$ & $\begin{array}{l}\text { Flexibility in billing and payment conditions, increasing } \\
\text { goodwill between airlines and the provider. }\end{array}$ \\
\hline \multirow[t]{3}{*}{ Risk } & Labor union $\left(\mathrm{C}_{9}\right)$ & $\begin{array}{l}\text { Outsourcing may be accompanied by the possibility of } \\
\text { layoffs and disturbances within the airline. The employees' } \\
\text { strike of outsourcing provider could cause chaos in flight } \\
\text { schedules. }\end{array}$ \\
\hline & $\begin{array}{l}\text { Loss of } \\
\text { management } \\
\text { control }\left(\mathrm{C}_{10}\right)\end{array}$ & $\begin{array}{l}\text { Able management of the provider may not provide good } \\
\text { service and may cause potential flight safety problems. }\end{array}$ \\
\hline & $\begin{array}{l}\text { Information } \\
\text { security } \\
\left(\mathrm{C}_{11}\right)\end{array}$ & $\begin{array}{l}\text { Mutual trust-based information sharing between the airline } \\
\text { and the provider is necessary for both the continuance of the } \\
\text { agreement and also for the security of confidential } \\
\text { information. }\end{array}$ \\
\hline
\end{tabular}

4.3 Measuring the relationships among dimensions

Since the partner selection systems are complex, it is not appropriate to assume the elements within systems are independent. Therefore, we sought to find the important criteria of evaluation systems and measure the relationships among these dimensions. Following the DEMATEL procedures described in Section 3.1, managers were asked to score the relationships among dimensions. The average initial direct-relation matrix $\boldsymbol{A}$ is a $4 \times 4$ matrix obtained by pair-wise comparisons in terms of influences and directions between dimensions, as shown in Table 2.

Table 2. Initial influence matrix

\begin{tabular}{lllll}
\hline & Compatibility & Quality & Cost & Risk \\
\hline Compatibility & 0.0 & 3.62 & 1.24 & 3.45 \\
Quality & 1.32 & 0.00 & 2.22 & 2.98 \\
Cost & 1.84 & 3.21 & 0.00 & 1.64 \\
Risk & 3.30 & 2.64 & 2.82 & 0.00 \\
\hline
\end{tabular}

As matrix $\boldsymbol{A}$ shows, the normalized direct-relation matrix $\boldsymbol{D}$ is calculated through equations (1), (2), and (3). Then, by using equation (5), total-influence matrix $\boldsymbol{T}$ is derived as indicated in Table 3 . Also, by using equations (7) and (8), the sum of influence given to and received by each dimension is shown in Table 4 . The $r_{i}+c_{i}$ value represents the total influence levels, and $r_{i}-c_{i}$ represents net influence levels, where the positive values indicate that it will influence other dimensions more than other dimensions influence it. Table 4 indicates that compatibility has the largest net influence levels.

Table 3. Total influence matrix

\begin{tabular}{lllll}
\hline & Compatibility & Quality & Cost & Risk \\
\hline Compatibility & 0.64 & 1.22 & 0.84 & 1.13 \\
Quality & 0.63 & 0.76 & 0.77 & 0.92 \\
Cost & 0.52 & 0.91 & 0.50 & 0.73 \\
Risk & 0.90 & 1.19 & 0.95 & 0.87 \\
\hline
\end{tabular}


Table 4. The sum of influence given to and received by dimensions

\begin{tabular}{lll}
\hline Dimensions & $r_{i}+c_{i}$ & $r_{i}-c_{i}$ \\
\hline Compatibility & 6.51 & 1.14 \\
Quality & 7.15 & -1.00 \\
Cost & 5.71 & -0.40 \\
Risk & 7.55 & 0.26 \\
\hline
\end{tabular}

According to the results of DEMATEL, the threshold value 0.9 was decided through managers' discussions. A value under 0.9 creates too complex a relationship in the whole system; the relationship is not prohibitively obvious once exceeding 0.9 . Based on the above threshold value, the IRM of DEMATEL method is obtained and shown in Fig. 3.

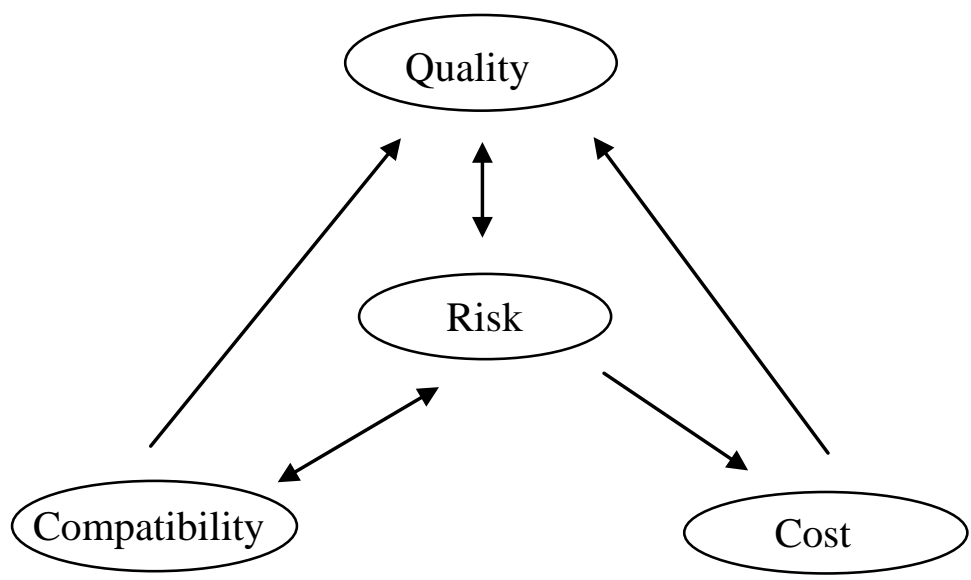

Fig. 3. Impact relationship map (IRM)

\subsection{Deriving the weights of criteria in evaluating systems}

After determining the relationship structure between dimensions of the evaluating systems, the ANP method is applied to derive the weights of the criteria. The first step of the ANP is to compare the relative importance of each criterion based on the IRM. For example, the managers were asked to respond to a series of questions, such as "For the relationship, how much more important is one of the considered criteria over another?” These pairwise comparisons are based on Saaty's 9-point scale and represent the importance of one element over another (where $1=$ equal importance and 9 $=$ extreme importance of one element over another). As the local weights of these criteria are obtained through the principal eigenvector of comparison, the unweighted supermatrix can be formed, as in Table 5.

Table 5. The unweighted supermatrix

\begin{tabular}{llllllllllll}
\hline & $\mathrm{C}_{1}$ & $\mathrm{C}_{2}$ & $\mathrm{C}_{3}$ & $\mathrm{C}_{4}$ & $\mathrm{C}_{5}$ & $\mathrm{C}_{6}$ & $\mathrm{C}_{7}$ & $\mathrm{C}_{8}$ & $\mathrm{C}_{9}$ & $\mathrm{C}_{10}$ & $\mathrm{C}_{11}$ \\
\hline $\mathrm{C}_{1}$ & 0 & 0 & 0 & 0 & 0 & 0 & 0 & 0 & 0.18 & 0.20 & 0.07 \\
$\mathrm{C}_{2}$ & 0 & 0 & 0 & 0 & 0 & 0 & 0 & 0 & 0.05 & 0.05 & 0.08 \\
$\mathrm{C}_{3}$ & 0 & 0 & 0 & 0 & 0 & 0 & 0 & 0 & 0.10 & 0.08 & 0.18 \\
$\mathrm{C}_{4}$ & 0.10 & 0.12 & 0.06 & 0 & 0 & 0 & 0.17 & 0.17 & 0.05 & 0.14 & 0.11 \\
$\mathrm{C}_{5}$ & 0.30 & 0.22 & 0.19 & 0 & 0 & 0 & 0.39 & 0.35 & 0.08 & 0.11 & 0.11 \\
$\mathrm{C}_{6}$ & 0.19 & 0.28 & 0.27 & 0 & 0 & 0 & 0.44 & 0.48 & 0.21 & 0.09 & 0.11 \\
$\mathrm{C}_{7}$ & 0 & 0 & 0 & 0 & 0 & 0 & 0 & 0 & 0.16 & 0.20 & 0.17 \\
$\mathrm{C}_{8}$ & 0 & 0 & 0 & 0 & 0 & 0 & 0 & 0 & 0.17 & 0.13 & 0.17 \\
$\mathrm{C}_{9}$ & 0.11 & 0.10 & 0.08 & 0.26 & 0.33 & 0.16 & 0 & 0 & 0 & 0 & 0 \\
$\mathrm{C}_{10}$ & 0.18 & 0.16 & 0.11 & 0.33 & 0.33 & 0.54 & 0 & 0 & 0 & 0 & 0 \\
\hline
\end{tabular}




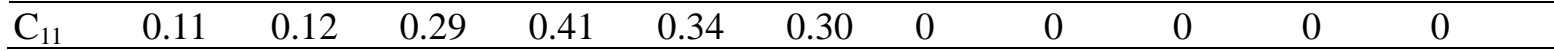

In the next step, by calculating the limiting power of the weighted supermatrix, equation (11) is applied until a steady state condition is reached (Table 6). Each row represents the weight of each criterion. As can be found in Table 6, the top three priorities in the evaluating systems are: loss of management control (15.6\%), customer satisfaction (13.6\%), and information security (13.4\%).

Table 6. The weighted supermatrix

\begin{tabular}{|c|c|c|c|c|c|c|c|c|c|c|c|}
\hline & $\mathrm{C}_{1}$ & $\mathrm{C}_{2}$ & $\mathrm{C}_{3}$ & $\mathrm{C}_{4}$ & $\mathrm{C}_{5}$ & $\mathrm{C}_{6}$ & $\mathrm{C}_{7}$ & $\mathrm{C}_{8}$ & $\mathrm{C}_{9}$ & $\mathrm{C}_{10}$ & $\mathrm{C}_{11}$ \\
\hline$\overline{\mathrm{C}_{1}}$ & 0.057 & 0.057 & 0.057 & 0.057 & 0.057 & 0.057 & 0.057 & 0.057 & 0.057 & 0.057 & 0.057 \\
\hline $\mathrm{C}_{2}$ & 0.023 & 0.023 & 0.023 & 0.023 & 0.023 & 0.023 & 0.023 & 0.023 & 0.023 & 0.023 & 0.023 \\
\hline $\mathrm{C}_{3}$ & 0.046 & 0.046 & 0.046 & 0.046 & 0.046 & 0.046 & 0.046 & 0.046 & 0.046 & 0.046 & 0.046 \\
\hline $\mathrm{C}_{4}$ & 0.074 & 0.074 & 0.074 & 0.074 & 0.074 & 0.074 & 0.074 & 0.074 & 0.074 & 0.074 & 0.074 \\
\hline $\mathrm{C}_{5}$ & 0.117 & 0.117 & 0.117 & 0.117 & 0.117 & 0.117 & 0.117 & 0.117 & 0.117 & 0.117 & 0.117 \\
\hline $\mathrm{C}_{6}$ & 0.136 & 0.136 & 0.136 & 0.136 & 0.136 & 0.136 & 0.136 & 0.136 & 0.136 & 0.136 & 0.136 \\
\hline $\mathrm{C}_{7}$ & 0.068 & 0.068 & 0.068 & 0.068 & 0.068 & 0.068 & 0.068 & 0.068 & 0.068 & 0.068 & 0.068 \\
\hline $\mathrm{C}_{8}$ & 0.058 & 0.058 & 0.058 & 0.058 & 0.058 & 0.058 & 0.058 & 0.058 & 0.058 & 0.058 & 0.058 \\
\hline $\mathrm{C}_{9}$ & 0.092 & 0.092 & 0.092 & 0.092 & 0.092 & 0.092 & 0.092 & 0.092 & 0.092 & 0.092 & 0.092 \\
\hline $\mathrm{C}_{10}$ & 0.156 & 0.156 & 0.156 & 0.156 & 0.156 & 0.156 & 0.156 & 0.156 & 0.156 & 0.156 & 0.156 \\
\hline $\mathrm{C}_{11}$ & 0.134 & 0.134 & 0.134 & 0.134 & 0.134 & 0.134 & 0.134 & 0.134 & 0.134 & 0.134 & 0.134 \\
\hline
\end{tabular}

\subsection{Using VIKOR to select the best outsourcing partner}

After the weights of evaluating systems are determined, the partner/provider selection of outsourcing is further illustrated based on the VIKOR method. There are 25 airline managers/chiefs conducting the assessment who have experience at the Los Angeles International Airport. For each ground service provider, managers/chiefs were asked to evaluate the level of satisfaction for each criterion, as indicated in the proposed evaluating systems. The normalized performance score $[0,1]$ for each provider is shown in Table 7 . For confidential reasons, the names of the providers have been concealed and represented as $A_{1}$ to $A_{4}$.

Table 7. Performance matrix of service providers on each criterion

\begin{tabular}{lccccc}
\hline Airlines & Weights & $A_{1}$ & $A_{2}$ & $A_{3}$ & $A_{4}$ \\
\hline Compatibility $\left(\mathrm{D}_{1}\right)$ & & & & & \\
Relationship $\left(\mathrm{C}_{1}\right)$ & 0.057 & 0.692 & 0.731 & 0.841 & 0.712 \\
Flexibility $\left(\mathrm{C}_{2}\right)$ & 0.023 & 0.713 & 0.750 & 0.860 & 0.784 \\
Information sharing $\left(\mathrm{C}_{3}\right)$ & 0.046 & 0.681 & 0.722 & 0.839 & 0.771 \\
Quality $\left(\mathrm{D}_{2}\right)$ & & & & & \\
Knowledge skills $\left(\mathrm{C}_{4}\right)$ & 0.074 & 0.720 & 0.753 & 0.821 & 0.736 \\
Customer satisfaction $\left(\mathrm{C}_{5}\right)$ & 0.117 & 0.742 & 0.702 & 0.784 & 0.730 \\
On time rate $\left(\mathrm{C}_{6}\right)$ & 0.136 & 0.685 & 0.752 & 0.815 & 0.755 \\
Cost $\left(\mathrm{D}_{3}\right)$ & & & & & \\
Cost saving $\left(\mathrm{C}_{7}\right)$ & 0.068 & 0.712 & 0.761 & 0.652 & 0.804 \\
Flexibility in billing $\left(\mathrm{C}_{8}\right)$ & 0.058 & 0.743 & 0.724 & 0.681 & 0.752 \\
Risk (D) & & & & & \\
Labor unions $\left(\mathrm{C}_{9}\right)$ & 0.092 & 0.772 & 0.731 & 0.742 & 0.791 \\
Loss of management control $\left(\mathrm{C}_{10}\right)$ & 0.156 & 0.754 & 0.732 & 0.788 & 0.772 \\
Information security $\left(\mathrm{C}_{11}\right)$ & 0.134 & 0.732 & 0.757 & 0.773 & 0.781 \\
\hline
\end{tabular}

Using the performance data in Table 7 and criterion weights in Table 6, the $S_{i}, Q_{i}$, and $R_{i}$ value were calculated using equations (15), (16), and (17). For comparison, the results of the traditional simple additive weight (SAW) method is also illustrated (Table 8). Since $R_{i}$ represents the gap between the alternative and ideal solutions, a smaller $R_{i}$ value is desirable. It is observed that $A_{4}$ contains the 
smallest gap according to a VIKOR analysis, while $A_{3}$ holds the highest value based on the SAW method.

Table 8. Results of the VIKOR and SAW analysis

\begin{tabular}{lllll}
\hline Service provider & $S_{i}$ & $Q_{i}$ & VIKOR $\left(R_{i}\right)$ & SAW \\
\hline$A_{1}$ & 0.262 & 0.262 & $0.291(4)$ & $0.698(4)$ \\
$A_{2}$ & 0.252 & 0.298 & $0.275(2)$ & $0.709(3)$ \\
$A_{3}$ & 0.212 & 0.348 & $0.280(3)$ & $0.748(1)$ \\
$A_{4}$ & 0.228 & 0.288 & $0.258(1)$ & $0.733(2)$ \\
\hline
\end{tabular}

Parentheses ( ) denotes rankings.

\section{Discussion}

The proposed hybrid model provides a systemically analytic model for the selection of outsourcing providers. Besides including multiple criteria, the model also considers the interdependencies among dimensions. Moreover, provider selection is based on the gap from the ideal solution that differs from the conventional aggregated method, i.e., the SAW method. The model can simultaneously consider the strategy of maximum group utility $\left(S_{i}\right)$ and minimum individual regret $\left(Q_{i}\right)$ while quantifying many subjective judgments, which is necessary for the evaluation of different alternative providers. Another advantage of this model is that supports group decision-making while also enabling us to document the various considerations in the decision-making process. This documentation is useful if the results are to be communicated to various interest groups.

In this study, the results indicate that provider $A_{4}$ is the first choice of the case company, based on the proposed hybrid model. The ranks of the overall scores of the four candidates were found to be $A_{4} \succ A_{2} \succ A_{3} \succ A_{1}$, where $\mathrm{A} \succ \mathrm{B}$ represents that $\mathrm{A}$ is preferred to $\mathrm{B}$. However, the results of traditional SAW indicate that the ranking is $A_{3} \succ A_{4} \succ A_{2} \succ A_{1}$, which is different from the results of our proposed model. This is because the proposed model employed the two concepts of the distance, i.e., $S_{i}$ and $Q_{i}$. The ranking index $R_{i}$ represents the overall gaps between the alternative and ideal points. Additionally, the aspired/desired/ideal points denote points at which all provider criteria are optimized, thus emphasizing the gaps between the appropriate provider and its ideal points. Managers can proceed to make improvements when they are aware of these gaps from the aspired/desired/ideal levels. Furthermore, the proposed model can easily be extended in other applications. Decision-makers can select the suitable weights $(v)$ found in Equation (17) according to their needs. If they are concerned about both maximum group utility and individual regret, then $v=0.5$ would be used (in our case study); if they are concerned about maximum group utility, then $v=1$ would be used; if they are concerned about individual regret, then $v=0$ would be used. It is pertinent here to discuss the priority values of the criteria, which influence this decision. From Table 7, it is observed that loss of management control (0.156) is the most important criterion in provider selection. It was followed by on-time rates (0.136), information security (0.134), and customer satisfaction (0.117). However, these results do not necessarily imply that Eva Air pays less attention to compatibility. In fact, Table 4 indicates that compatibility has the highest degree of $\left(r_{i}-\right.$ $c_{i}$ ), which shows that compatibility will influence other dimensions more than it influenced by others. That means that compatibility between the user and provider helps ascertain that the provider is capable of fulfilling the user's needs in various aspects, such as cost and quality. On the other hand, risk has the highest value $\left(r_{i}+c_{i}\right)$, which means it will affect other dimensions and will also be dramatically affected by others. It may be emphasized again that the proposed hybrid model is capable of handling such interdependencies.

\section{Conclusion}

This study suggests a decision model for outsourcing that considers interdependencies between criteria and shows how the model may be applied in real-world decision processes. Factors affecting outsourcing partner selection were investigated in multiple criteria (including compatibility, quality, cost, and risk) in order to avoid the mistakes made by traditional outsourcing decisions. These traditional decisions generally only consider cost as a criterion, or assume that the criteria are 
independent. Also, our hybrid model considers both maximum group utility and individual regret to measure the gaps between alternative and ideal solutions, which is a completely different approach method than the conventional SAW method.

Our results have several implications for outsourcing partner selection process. First, managers considering outsourcing should identify its selection criteria and weights very carefully. Various criteria and weights may result in a different solution. In addition, since it is up to managers to assess the criteria and their relative impact on provider selection, they need to have a clear picture of their evaluating systems. In addition, managers of outsourcing providers should understand which factors can affect the outsourcing partner selection. For example, managers much make special efforts to enhance their compatibility with the users, because a provider's compatibility plays a significant role in the decision model for outsourcing activities.

\section{REFERENCES}

Belton, V., \& Stewart, T.J. (2002). Multiple Criteria Decision Analysis: An Integrated Approach, Kluwer Academic Publisher.

Chiu, Y.J., Chen, H.C., \& Tzeng, G.H. (2006). Marketing strategy based on customer behavior for the LCD-TV. International Journal of Management and Decision Making, 7(2/3), 143-165.

Ellram, L.M., Tate, W.L., \& Billington, C. (2008). Offshore outsourcing of professional services: A transaction cost economics perspective. Journal of Operations Management, 26(2), 148-163.

Hamel, G., \& Prahalad, C.K. (1994). Competing for the future. Harvard Business School Press, MA, 84-85.

Howell, J. (1999). Research and technology outsourcing. Technology Analysis \& Strategic Management, 11(1), 17-29.

Hsu, P.F., \& Hsu, M.G. (2008). Optimizing the information outsourcing practices of primary care medical organizations using entropy and TOPSIS. Quality \& Quantity, 42(2), 181-201.

Huang, J.J., Tzeng, G.H., \& Ong, C.S. (2005). Multidimensional data in multidimensional scaling using the analytic network process. Pattern Recognition Letters, 26(6), 755-767.

Jharkharia, S., \& Shankar, R. (2007). Selection of logistics service provider: An analytic network process (ANP) approach. OMEGA, 35(3), 274-289.

Kedia, B.L., \& Mukherjee, D. (2008). Understanding offshoring: A research framework based on disintegration, location and externalization advantages. Journal of World Business, forthcoming.

Lee, J.N., \& Kim, Y.G. (2005). Understanding outsourcing partnership: a comparison of three theoretical perspectives. IEEE Transaction on Engineering Management, 52(1), 43-57.

Liou, J.H., Tzeng, G.H., \& Chang, H.C. (2007). A novel hybrid model for safety measurement of airlines. Journal of Air Transport Management, 13(4), 243-249.

McCarthy, I. \& Anagroustou, A. (2004). The impact of outsourcing on the transaction costs and boundaries of manufacturing. International Journal of Production Economics, 88(1), 61-71.

Opricovic, S. (1998). Multicriteria Optimization of Civil Engineering Systems, Faculty of Civil Engineering, Belgrade.

Opricovic, S., \& Tzeng, G.H. (2004). Compromise solution by MCDM methods: A comparative analysis of VIKOR and TOPSIS. European Journal of Operation Research, 156(2), 445-455. 
Opricovic, S., \& Tzeng, G.H. (2007). Extended VIKOR method in comparison with outranking methods. European Journal of Operational Research, 178(2), 514-529.

Saaty, T.L. (1996). Decision making with dependence and feedback: Analytic Network Process. RWS publications. Pittsburgh.

Saaty, T.L. (1999). Fundamentals of the analytic network process. Japan, Kobe: The International Symposium on the Analytic Hierarchy Process.

Sarder, Md B., Rogers, K.J., \& Prater, E. (2006). Outsourcing SWOT analysis fro some US industry. PICMET 2006 Proceeding, 9-13 July, Istanbul, Turkey.

Tamura, M., Nagata, H., \& Akazawa, K. (2002). Extraction and systems analysis of factors that prevent safety and security by structural models. In $41^{\text {st }}$ SICE annual conference, Osaka, Japan.

Tsai, W.H., \& Chou, W.C. (2009). Selecting management systems for sustainable development in SMEs: A novel hybrid model based on DEMATEL, ANP, and ZOGP. Expert Systems with Applications, 36( 2), Part 1, 1444-1458.

Tseng, M.L. (2009). Using the extension of DEMATEL to integrate hotel service quality perceptions into a cause-effect model in uncertainty. Expert Systems with Applications. Forthcoming.

Tzeng, G.H., Chiang, C.H., \& Li, C.W. (2007). Evaluating intertwined effects in e-learning programs: A novel hybrid MCDM model based on factor analysis and DEMATEL. Expert Systems with Applications, 32(4), 1028-1044.

Verma, P. (2005). Outsourcing no more on US’ hot list. The Economic Times, April 25.

Wang, J.J., \& Yang, D.L. (2007). Using a hybrid multi-criteria decision aid method for information system outsourcing. Computers \& Operations Research, 34(12), 3691-3700.

Yang, D.H., Kim, S, Nam, C., \& Min, J.W. (2007). Developing a decision model for business process outsourcing. Computers \& Operations Research, 34(12), 3769-3778. 